\title{
Endoscopic removal of esophageal and gastric foreign bodies in dogs: the prevalence, risk factors and efficacy of removal
}

\author{
Iva Šmit, Martina Crnogaj*, Mirna Brkljačić, Dalibor Potočnjak, \\ Marin Torti, Ivana Kiš, Vladimir Mrljak, Ines Jović, and Vesna Matijatko
}

Clinic for Internal Diseases, Faculty of Veterinary Medicine, University of Zagreb, Zagreb, Croatia

\begin{abstract}
ŠMIT, I., M. CRNOGAJ, M. BRKLJAČIĆ, D. POTOČNJAK, M. TORTI, I. KIŠ, V. MRLJAK, I. JOVIĆ, V. MATIJATKO: Endoscopic removal of esophageal and gastric foreign bodies in dogs: the prevalence, risk factors and efficacy of removal. Vet. arhiv 88, 481-496, 2018.
\end{abstract}

\section{ABSTRACT}

Esophageal and gastric foreign bodies (FB) are a relatively common finding in dogs, and in certain cases can also be life threatening. Endoscopic removal of esophageal and gastric FB is the preferred treatment option. This retrospective study evaluated the medical records of 100 dogs that had undergone endoscopic removal of esophageal or gastric FB. The information obtained from the medical records included: age, breed, sex, duration and type of clinical signs, the type and location of the foreign body, the success of endoscopic removal, and short-term complications and outcome. The majority of esophageal FB were bones, while the most common type of gastric FB were toys. Even though the overall complication rate is low, in dogs with esophageal FB the development of complications is associated with the longer duration of clinical signs, whilst in gastric FB a higher rate of complications is associated with FB migration.

Key words: dog; foreign body; endoscopy; esophagus; stomach

\section{Introduction}

In dogs, occasional ingestion of foreign bodies (FB) can occur, with the most common site of FB location in the gastrointestinal tract (GI) being the esophagus and stomach. Unresolved FB can become life threatening.

Endoscopy is a procedure that allows minimally invasive diagnostic and therapeutic examination of the GI tract. Therefore, endoscopic removal of esophageal and gastric FB is the preferred treatment option. Like any other procedure, it is not without risk.

\footnotetext{
${ }^{*}$ Corresponding author:

Assist. Prof. Martina Crnogaj, PhD, Clinic for Internal Diseases, Faculty of Veterinary Medicine, University of Zagreb, Heinzelova 55, Zagreb, Croatia, Phone: +385 12390 111; E-mail: martina.crnogaj@vef.hr
} 
Clinical signs related to FB lodgment in the esophagus are usually acute and can include salivation, dysphagia, retching, regurgitation, lethargy and anorexia (TAMS, 2003). The severity of clinical signs depends on the size and configuration of the FB, its location, the duration of obstruction, and the presence or absence of complications (KING, 2001). Sometimes the FB remains undetected in the esophagus for a number of days or weeks. Esophageal FB mostly lodge at the neck part of the esophagus (thoracic inlet), or in the thoracic part of the esophagus (the heart base and cranial to the lower esophageal sphincter) (SEILER et al., 2001).

Removal of esophageal FB can be accomplished by endoscopic retrieval, by manipulation of the FB into the stomach and gastrotomy/dissolution, or by esophagotomy.

Endoscopic esophageal FB removal has a complication rate ranging from $10 \%$ to 29\% (GIANELLA et al., 2009; DEROY et al., 2015). The most common complications resulting from an esophageal FB are esophagitis, perforation of the esophagus, pneumomediastinum/pyomediastinum, pneumothorax/pyothorax and strictures (SHERDING, 2013), with an overall survival rate of 79-93\% (HOULTON et al., 1985; MOORE, 2001; SALE and WILLIAMS, 2006).

Gastric FBs are a common finding in dogs, and they are usually asymptomatic or they may cause symptoms when the pylorus becomes obstructed or gastric mucosal damage occurs. Removal of a gastric FB may be accomplished by endoscopic removal or gastrotomy. The most common complications due to gastric FB are gastric ulceration, gastric perforation or complications related to the composition of the FB (e.g. lead poisoning) (STURGESS, 2000; SHERDING, 2013).

\section{Materials and methods}

Clinical cases. The medical records were reviewed of dogs with esophageal and gastric FBs that had undergone endoscopic removal at the Clinic for Internal Medicine, Faculty of Veterinary Medicine, University of Zagreb, Croatia, between January 2007 and February 2017. The data retrieved included history, clinical signs at presentation, duration of clinical signs, type, number and location of FBs, success of endoscopic removal, shortterm complications and outcome. All canine patients admitted to the hospital during the study period were used as the general hospital population to investigate FB prevalence and breed prevalence in esophageal and gastric FB.

The diagnosis of esophageal or gastric FB was made using history, physical examination results, and lateral thoracic and/or abdominal radiography, or positive contrast radiography. The owners described the clinical symptoms and duration of symptoms upon admission.

All dogs were categorized as small, medium, large and giant breeds, according to their wither height and weight. 
Endoscopy. During the removal procedure, a video endoscopy system was used (Olympus CLV- U20, GIF-XQ240, insertion tube: $9.0 \mathrm{~mm}$, channel: $2.8 \mathrm{~mm}$, working length: $1030 \mathrm{~mm}$ ). Depending on the type, size and location of the FB, grasping forceps or a basket were used for retrieval of the foreign body.

Statistical analysis. For descriptive analyses of the continuous data, the mean \pm standard error and the range of values are reported. For categorical data, frequencies and percentages are given. Computer software IBM SPSS Statistics, version 19.0.0.1., was used for statistical analysis. The Student $t$-test was used to analyze continuous data. Pearson's Chi Square test was used to compare groups with categorical data. A P $<0.05$ was considered significant.

\section{Results}

During the study period, 100 dogs underwent endoscopic removal of an esophageal or gastric FB, which represents a prevalence of 0.47 percent of the general canine hospital population in the study period $(100 / 21,490)$. The prevalence of esophageal FB was $0.22 \%$, and of gastric FB $0.24 \%$. In our study none of the dogs had esophageal and gastric FB at the same time.

In 48 dogs the FB was located in the esophagus, and in 52 dogs the stomach. Esophageal FB were found in both the cervical and thoracic parts of the esophagus, but more often in the thoracic part of the esophagus (Fig. 1). The vast majority of esophageal FB were bones and cartilage (Fig. 2).

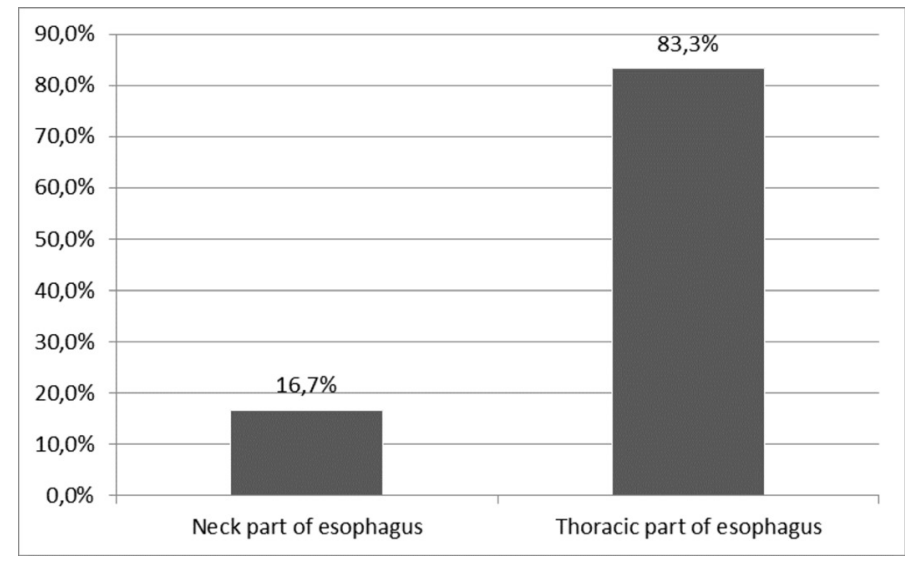

Fig. 1. Localization of esophageal foreign bodies in dogs 
I. Šmit et al.: Endoscopic removal of esophageal and gastric foreign bodies in dogs

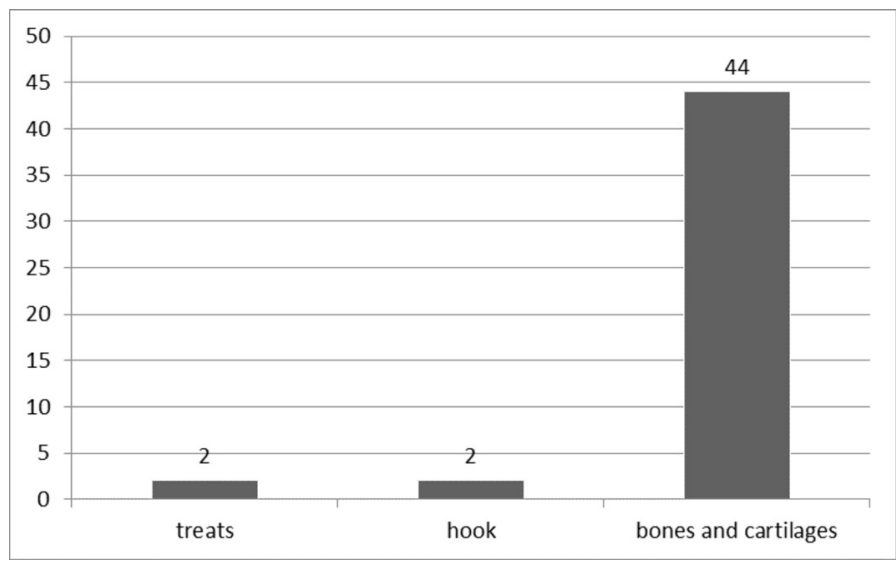

Fig. 2. Type of esophageal foreign bodies

The study population consisted of dogs of 36 different breeds and 19 mixed-breed dogs, there were 52 small, 23 medium, 24 large and 1 giant breeds, respectively. 54 dogs were male, and 46 were female (Tables 1 and 2).

Dogs with esophageal FB were categorized as small breed (37/48), medium breed (6/48), large breed (5/48), and dogs with gastric foreign FB were categorized as small breed (15/52), medium breed (17/52), large breed (19/52), and giant breed (1/52) ( Figs. 3 and 4$)$.

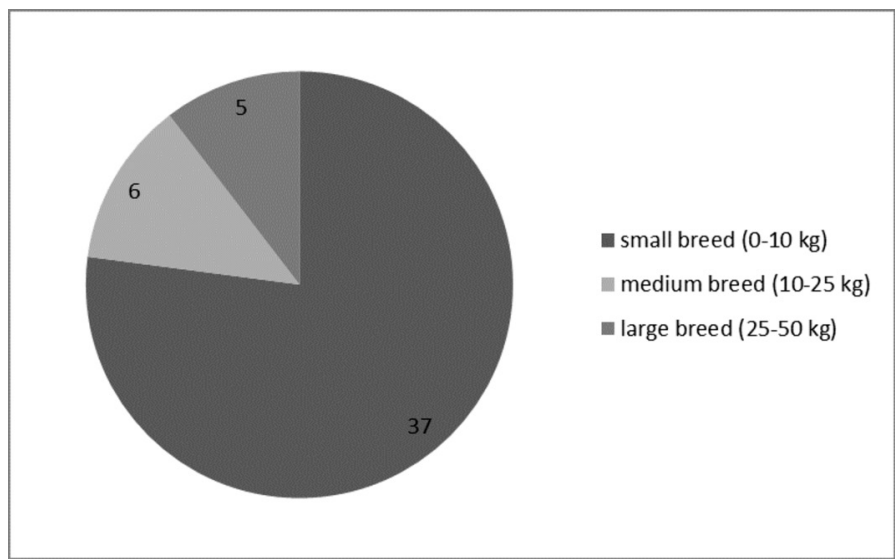

Fig. 3. Breed size in dogs with esophageal foreign bodies 
I. Šmit et al.: Endoscopic removal of esophageal and gastric foreign bodies in dogs

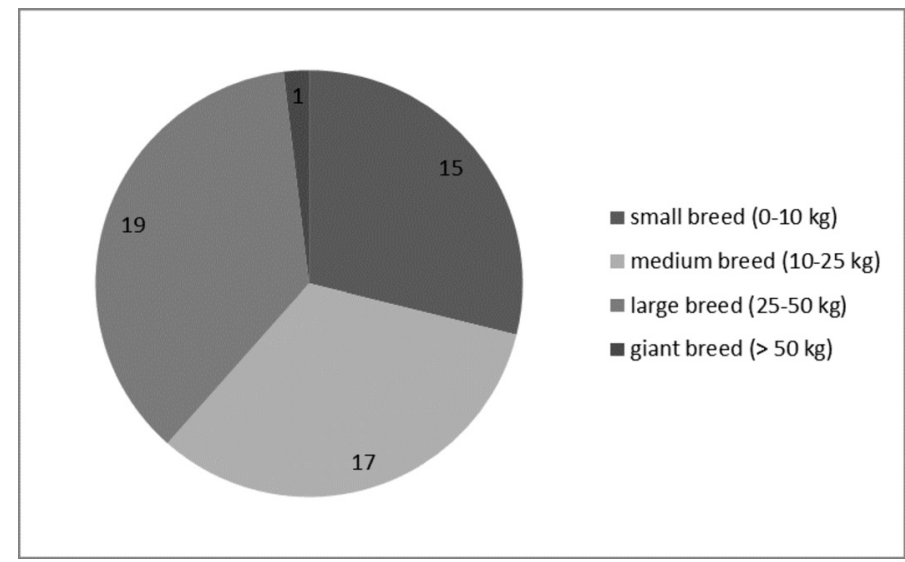

Fig. 4. Breed size in dogs with gastric foreign bodies

Table 1. Breed prevalence in esophageal foreign bodies

\begin{tabular}{|l|c|c|c|}
\hline Breed & $\begin{array}{c}\text { Number in study } \\
\text { population } \\
\mathrm{n}=48\end{array}$ & $\begin{array}{c}\text { \% in study } \\
\text { population } \\
\mathrm{n}=48\end{array}$ & $\begin{array}{c}\text { \% in general } \\
\text { hospital population } \\
\mathrm{n}=21490\end{array}$ \\
\hline West Highland White Terrier & 13 & 27 & 2.50 \\
\hline Shih Tzu & 4 & 8.30 & 1.90 \\
\hline Mixed breed & 6 & 12.50 & 26.60 \\
\hline Maltese & 3 & 6.30 & 4.90 \\
\hline Yorkshire Terrier & 3 & 6.30 & 1.50 \\
\hline Pekingese & 3 & 6.30 & 3.40 \\
\hline Miniature Pincher & 3 & 6.30 & 0.90 \\
\hline Golden Retriever & 2 & 4.20 & 3.80 \\
\hline Lhasa Apso & 2 & 4.20 & 0.20 \\
\hline Pug & 2 & 4.20 & 1.70 \\
\hline Samoyed & 1 & 2 & 0.80 \\
\hline German Spitz & 1 & 2 & 0.40 \\
\hline Jack Russell Terrier & 1 & 2 & 0.60 \\
\hline French Bulldog & 1 & 2 & 1.60 \\
\hline Cotton de Tulear & 1 & 2 & 0.10 \\
\hline Bernese Mountain Dog & 1 & 2 & 0.90 \\
\hline Alaskan Malamute & 1 & 2 & 0.60 \\
\hline
\end{tabular}


I. Šmit et al.: Endoscopic removal of esophageal and gastric foreign bodies in dogs

Table 2. Breed prevalence in gastric foreign bodies

\begin{tabular}{|l|c|c|c|}
\hline \multicolumn{1}{|c|}{ Breed } & $\begin{array}{c}\text { Number in study } \\
\text { population } \\
\mathrm{n}=52\end{array}$ & $\begin{array}{c}\text { \% in study } \\
\text { population } \\
\mathrm{n}=52\end{array}$ & $\begin{array}{c}\text { \% in general } \\
\text { hospital population } \\
\mathrm{n}=21490\end{array}$ \\
\hline Mixed breed & 13 & 25 & 26.60 \\
\hline Golden Retriever & 5 & 9.60 & 3.80 \\
\hline West Highland White Terrier & 2 & 3.80 & 2.50 \\
\hline Shih Tzu & 2 & 3.80 & 1.90 \\
\hline German Shorthaired Pointer & 2 & 3.80 & 0.50 \\
\hline French Bulldog & 2 & 3.80 & 1.60 \\
\hline Maltese & 2 & 3.80 & 4.90 \\
\hline Cane Corso & 2 & 3.80 & 0.40 \\
\hline Bull Terrier & 2 & 3.80 & 0.20 \\
\hline German Boxer & 2 & 3.80 & 1.60 \\
\hline Staffordshire Bull Terrier & 1 & 1.90 & 1.70 \\
\hline Medium Poodle & 1 & 1.90 & 3.20 \\
\hline Shiba Inu & 1 & 1.90 & 0.10 \\
\hline Irish Seter & 1 & 1.90 & 0.50 \\
\hline Samoyed & 1 & 1.90 & 0.80 \\
\hline Rottweiler & 1 & 1.90 & 1.70 \\
\hline Flat coated Retriever & 1 & 1.90 & 0.20 \\
\hline Pekingese & 1 & 1.90 & 3.40 \\
\hline Miniature Schnauzer & 1 & 1.90 & 1.20 \\
\hline Soft Coated Wheaten Terrier & 1 & 1.90 & 10.00 \\
\hline Hungarian Vizsla & 1 & 1.90 & 0.30 \\
\hline Labrador Retriever & 1 & 1.90 & 3.00 \\
\hline Yorkshire Terrier & 1 & 1.90 & 0.90 \\
\hline English Bulldog & 1 & 1.90 & 1.20 \\
\hline Doberman Pinscher & 1 & & 1.00 \\
\hline Bichon Frise & 1 & & \\
\hline Malinois & 1 & 1.90 & \\
\hline Beagle & 1 & & \\
\hline
\end{tabular}

The mean age of the dogs with esophageal FB was $4.7 \pm 3.9$ years (mean $\pm \mathrm{SD}$ ), with a range of 4 months to 14 years, and of dogs with gastric FB the mean age was $3.5 \pm 3.4$ years (mean $\pm \mathrm{SD})$, with a range of 2 months to 14 years.

Clinical signs with esophageal FB are shown in Fig. 5. 


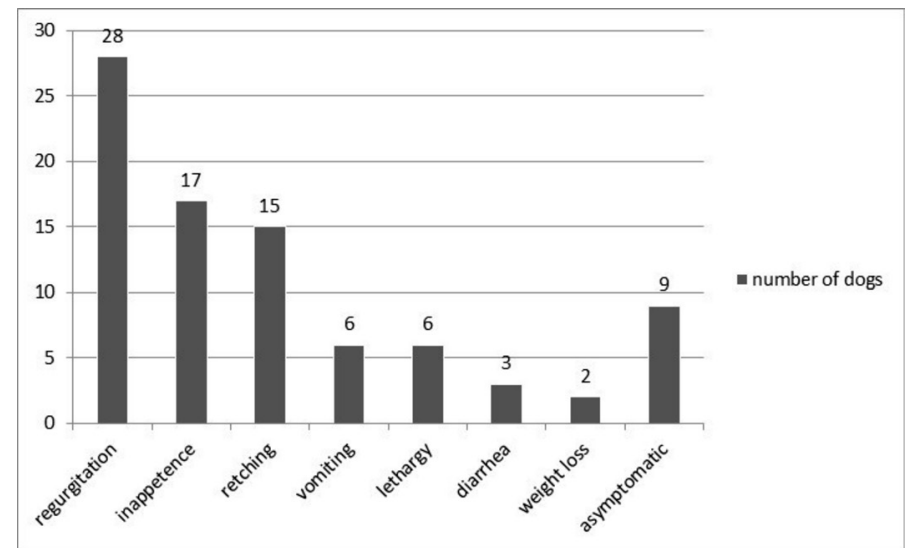

Fig. 5. Clinical signs in dogs with esophageal foreign bodies

Of the 48 dogs with esophageal FB, 18 were admitted on the day of FB ingestion, while the rest of the dogs (27/48) had had symptoms lasting from 1-15 days, except for $3 / 48$ dogs that had had symptoms for longer than 15 days. The duration of clinical signs before presentation in dogs with esophageal FB was significantly shorter for dogs without complications than for those with complications $(\mathrm{P}<0.05)$.

In dogs with gastric FB: 19/52 were admitted within 24 hours after the owners observed FB ingestion, 11/52 dogs had had symptoms that lasted 1-15 days, 16/52 dogs had had symptoms for longer than 15 days, and in 6/52 dogs gastric FB was an incidental finding.

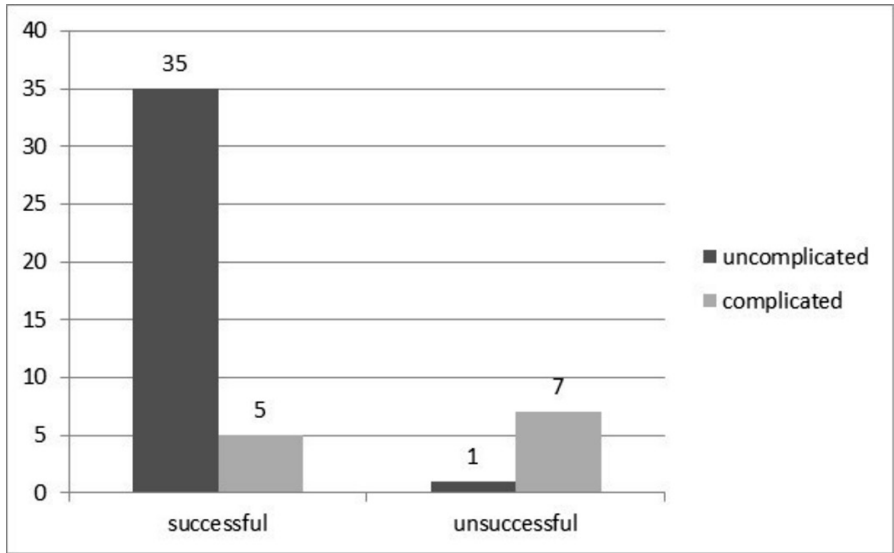

Fig. 6. Success of endoscopic retrieval of esophageal FB and appearance of complications $(n=48)$. 
Esophageal FBs were successfully removed in 40/48 dogs (83.3\%) (Fig. 6). Recorded complications in esophageal FB were esophageal perforation (7), esophagitis (3) and esophagitis with strictures (2). Unsuccessful esophageal FB removal was associated with a significantly increased risk of complications $(\mathrm{P}<0.05)$.

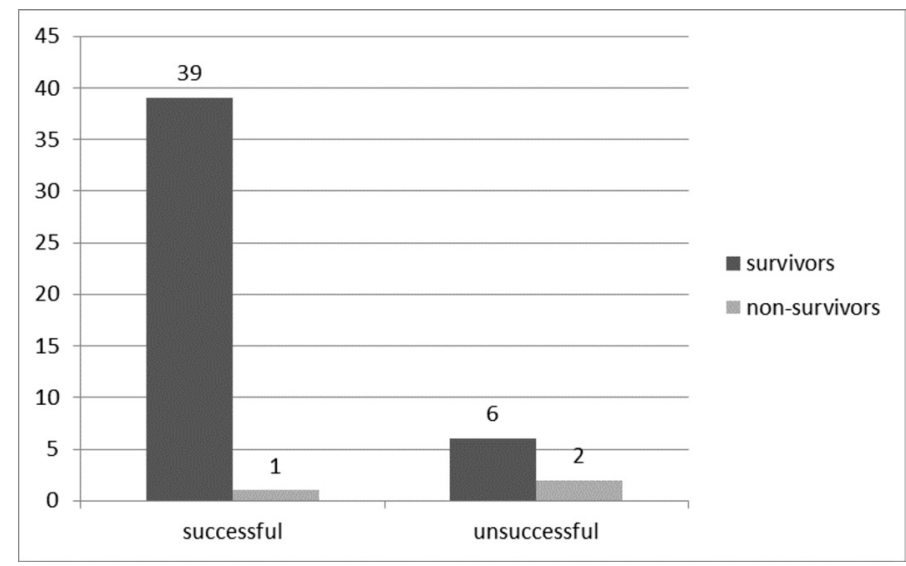

Fig.7. Success of endoscopic retrieval of esophageal foreign bodies and mortality $(n=48)$.

Mortality in the group of dogs with successfully removed esophageal FB was significantly lower $(1 / 40)$ than in the group experiencing unsuccessful endoscopic retrieval (2/8) (Fig. 7) $(\mathrm{P}<0.05)$.

Clinical signs with gastric FB are shown in Fig. 8. 
I. Šmit et al.: Endoscopic removal of esophageal and gastric foreign bodies in dogs

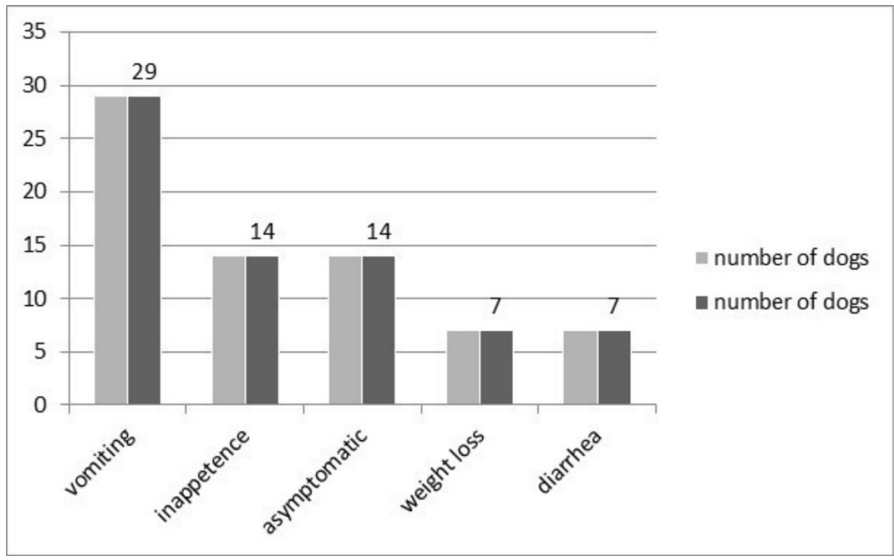

Fig. 8. Clinical signs in dogs with gastric foreign bodies

The gastric FB most commonly found were toys (16/52: balls, stuffed animals, etc.), other (12/52: undefined plastic or rubber pieces, wooden sticks, plastic bags, etc.) and metal FB (10/52: needles, buttons, buckles). 12 dogs (23\%) had more than one type of gastric FB.

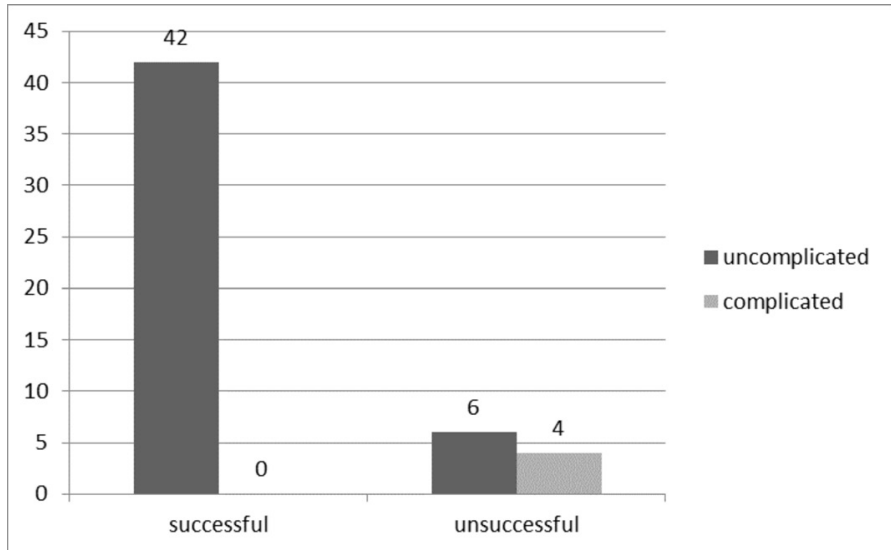

Fig. 9. Success of endoscopic retrieval of gastric foreign bodies and appearance of complications $(n=52)$.

Gastric FBs were successfully removed in 42/52 dogs.

Vet. arhiv 88 (4), 481-496, 2018 
Only 4 dogs with gastric FB had complications: gastric perforation (3), and one had gastric and liver perforation. All the complications in dogs were recorded when endoscopic removal was not performed because endoscopy was converted to surgery after endoscopic inspection (Fig. 9). In dogs with gastric FBs mortality was $0 \%$.

In all the 40 successful endoscopic removals of esophageal FB, grasping forceps were used, and for gastric FB grasping forceps were used in 33/48 dogs, and a basket in $15 / 48$ dogs.

\section{Discussion}

Esophageal and gastrointestinal FBs are a relatively common finding in small animal practice (POLLOCK, 1969; AUGUSTO et al., 2005; GIANELLA et al., 2009). The prevalence of esophageal FB was $0.22 \%$, while the prevalence of gastric FB was $0.24 \%$ of the entire canine hospital population. These results are similar to the results of GIANELLA et al. (2009). Esophageal FBs were slightly less frequent than the gastric ones. The vast majority of esophageal FBs were bones and cartilage (91.6\%), which is in accordance with other studies (reported range was 76.5\% - 86.7\%) (LUTHI and NIEGER, 1998; JUVET et al., 2010). This may be attributed to the eating habits of canidae, exposure to certain types of food, and the physical features of bones (strength and shape). Also, in accordance with other studies (SPIELMAN et al., 1992; LUTHI and NIEGER, 1998; JUVET et al., 2010), the distal part of the esophagus was found to be by far the most frequent site of entrapment ( $83 \%$ ), which is the consequence of the narrowing of the esophagus in its distal part and its limited ability to distend.

Since almost all esophageal FBs are bones, the diagnosis of the presence of an esophageal FB is usually straightforward, due to their radiopacity (SPIELMAN and al., 1992; LEIB and SARTOR, 2008; GIANELLA et al., 2009). All the esophageal FBs in the present study were diagnosed by radiography. The rest of the FBs were fishhooks and treats, findings that were similar to those reported in other studies (LEIB and SARTOR, 2008; GIANELLA et al., 2009). Common clinical signs, such as regurgitation, salivation, anorexia, retching, vomiting and diarrhea, are easily overlooked and attributed to acute gastroenteritis, so thoracic radiographs should be included in the workup of patients with such symptoms. This failure to recognize an FB as the cause of the aforementioned symptoms was also documented in this study, since all the dogs with prolonged duration of symptoms had been treated by their referring veterinarians for gastroenteritis.

In our study male dogs presented more frequently (54\%) which is contrary to the results obtained by LUTHI and NIEGER (1998) (36\% males). In the vast majority of other studies, sex was almost equally distributed (LEIB and SARTOR, 2008; JUVET et al., 2010). These results cannot be explained without data on sex distribution in the general hospital population, and these results were deficient in our study. 
The vast majority of dogs with esophageal FB were defined as small breed dogs (77\%), which is an even higher percentage than noted in the study by LUTHI and NIEGER (1998) (50\%). If we compare the size of FB to the size of the dog it is more likely that a FB of the same size would be trapped in the esophagus of a smaller dog.

West Highland white terriers and Shih Tzu were overrepresented breeds in our study of esophageal FBs. The overrepresentation of West Highland white terriers has already been well documented (LUTHI and NIEGER, 1998; JUVET et al., 2010). The assumption is that this is a consequence of the breed-specific anatomical configuration: a large head compared to body size, and the narrowing of the thoracic part of the esophagus (LUTHI and NIEGER, 1998). According to the author's knowledge, the only study that has documented the overrepresentation of Shih Tzu is the study conducted by LEIB and SARTOR (2008), but this study includes only dog treats as FBs in dogs. All the Shih Tzu dogs in our study had bones or cartilages as FBs. However, overrepresentation of this breed could be explained by similar reasons as for West Highland white terriers.

The ages of dogs with esophageal FBs were similar in the majority of studies (mean or average 5.7 years in the study by JUVET et al. (2010); 4 years in LEIB and SARTOR (2008), and 6.2 years by LUTHI and NIEGER (1998) as well as in our study (4.7 \pm 3.9 years (mean $\pm \mathrm{SD})$ ). Although the average age in these studies is very similar and it may be defined as young to middle-aged, the range is very wide ( 2 months to 17 years), so FB should be included as a differential diagnosis in dogs of all ages.

Unlike the relatively simple diagnosis of an esophageal FB, its removal can be more challenging.

Esophageal FB should be removed promptly to avoid serious complications due to pressure necrosis, such as perforation of the esophageal wall, mediastinitis, pleuritis and severe esophagitis with strictures (ROUSSEAU et al., 2007; LEIB and SARTOR, 2008; KEIR et al., 2010; BOYD et al., 2017). The overall rate of complications in similar studies was 10\%-29\% (LUTHI and NIEGER, 1998; JUVET et al., 2010; DEROY et al., 2015).

Endoscopic removal is usually the preferred method of FB removal because it is minimally invasive, it results in a lower rate of complications, and shorter and faster recovery (SALE and WILLIAMS, 2006; LEIB and SARTOR, 2008; GIANELLA et al., 2009). However, even successful endoscopic FB removal can result in complications (JUVET et al., 2010). The success of endoscopic esophageal FB removal ranged from 26 to 89 per cent in several studies (SPIELMAN and al., 1992; LUTHI and NIEGER, 1998; LEIB and SARTOR, 2008; JUVET et al., 2010). Compared to other studies, our rate of success $(88 \%)$ and the rate of complications $(25 \%)$ were similar.

Several studies (ROUSSEAU et al., 2007; THOMPSON et al., 2012) have reported a negative correlation between the duration of clinical signs and complications in dogs 
with esophageal FB. This study also revealed a significant association between the occurrence of complications and duration of symptoms $(\mathrm{P}<0.05)$, which is a consequence of the continuous and prolonged pressure of the FB against the esophageal wall, causing inflammation and necrosis.

In cases unresolved endoscopically or presumed perforation, surgery should be attempted. Due to its invasiveness, esophagotomy is a procedure with a higher rate of complications, significant cost and prolonged recovery (ZIMMER, 1984).

Esophageal FB is a life-threating condition. The mortality rate in other studies was 11.1\% (JUVET, 2010), 11.7\% (LUTHI and NIEGER, 1998), and 19\% (LEIB and SARTOR, 2008). The overall mortality rate in our study in dogs that had esophageal FB was $6.3 \%$. The mortality rate in cases in which esophageal FB was endoscopically removed was $2.5 \%$, and mortality was $25 \%$ in cases that were referred to surgery, which shows that the mortality rate was significantly higher in the group of dogs that underwent surgical removal of FB $(\mathrm{P}<0.05)$. These results confirm that cases of esophageal FB that cannot be removed by endoscopy and which underwent surgical removal are related to a poorer outcome. Moreover, the only dog in the present study that died after successful endoscopic removal of an esophageal FB died due to the development of cardiogenic pulmonary edema caused by severe myxomatous mitral valve disease, and not FB complications.

The most severe complications were noted in dogs that swallowed dog treats (esophagitis, extreme thinning of the esophageal wall, sepsis, gastric tube placement) which is in accordance with the higher percentage of complications (19.4\%) and higher mortality rate $(25 \%)$ noted in the study on FB obstruction caused by dental chew treats published by LEIB and SARTOR (2008). Furthermore, the authors suggest the problem is more frequent in small dogs weighing less than $8 \mathrm{~kg}$, which was also the case with our patient (Pomeranian spitz, weighing $3 \mathrm{~kg}$ ). The proposed explanation is that the severe esophageal lesions arose as a consequence of the pressure that the smooth contours of the dental chew treat caused, whilst pointed irregular surfaces (like bones) frequently cause perforation. The smooth surface of such FBs causes difficulties in oral endoscopic removal; such as in this case, where the FB was pushed into the stomach. LEIB and SARTOR (2008) reported that the success rate of oral removal of treats was only $26 \%$ compared to $86 \%$ for oral removal of other esophageal FBs (mostly bones) in the study by GIANELLA et al. (2009).

Contrary to esophageal FB, most gastric FBs are inedible objects. The most commonly found gastric FBs were toys (balls and stuffed toys, 31\%), since all other, edible objects are dissolved by gastric acid.

Clinical signs with gastric FBs included vomiting (56\%), inappetence (27\%), diarrhea $(13 \%)$, weight loss $(13 \%)$, or they are asymptomatic $(27 \%)$, which is comparable with 


\section{I. Šmit et al.: Endoscopic removal of esophageal and gastric foreign bodies in dogs}

other published studies: vomiting (75\%), inappetence (14\%), weight loss $(11 \%)$, and asymptomatic (31\%) (GIANELLA et al, 2009). In 27\% of dogs with gastric FB that were asymptomatic the findings were coincidental or the owner saw the dog swallowing the FB.

The success rate of endoscopic removal of gastric FBs in this study was $83 \%$. There is a lack of scientific data on gastric FBs and their endoscopic removal, but our success rate was in agreement with that of GIANELLA et al. (2009), which was 78\%. All unsuccessfully removed gastric FBs were either too large (bones, balls, large sharp plastic objects) or sharp objects in which perforation was seen or suspected (needle, rib bone).

All the complications documented in this study were complications due to migration of gastric FBs. The complications noted were not a consequence of endoscopic removal, but the reason for conversion to surgical treatment. Gastric perforation was observed in 4 dogs $(7.6 \%)$, and in one dog (1.9\%) gastric and hepatic perforation was observed. GIANELLA et al. (2009) reported similar occurrence of gastric perforation (6.6\%). There was no mortality in dogs with gastric FB reported in our study.

It should be pointed out that this study has similar limitations as all retrospective studies. The limitations, such as descriptions of esophageal or gastric conditions, were the consequence of subjective clinician assessment because there were various numbers of different clinicians involved in patient examinations. Also, there was lack of complete laboratory data since some patients were referred as emergency patients during the night and at weekends. That is the reason why we did not include laboratory results in our study.

\section{Conclusions}

The present study documents differences in the appearance and type of esophageal and gastric FBs, and between the clinical signs and complications in successfully and unsuccessfully removed FBs. Even though the overall complication rate is low, potentially life-threatening complications may develop, especially in prolonged and untreated cases of FB in the esophagus and in cases of gastric FBs that are prone to migration. That is the reason for the need for detailed diagnostics (including radiographs) and prompt treatment, preferably by endoscopy, since it is a minimally invasive procedure with a high success rate. Endoscopic removal of FB has a lower complication rate and a lower mortality rate, which contributes to shorter hospital stay, faster recovery and lower financial costs when compared to surgery.

\section{Acknowledgements}

The authors are grateful to Valentina Plichta, DVM and Mirta Vučković, DVM (Faculty of Veterinary Medicine, University of Zagreb) for their help in managing the patients. 
I. Šmit et al.: Endoscopic removal of esophageal and gastric foreign bodies in dogs

\section{References}

AUGUSTO, M., M. KRAIJER, K. M. PRATSCHKE (2005): Chronic oesophageal foreign body in a cat. J. Feline Med. Surg. 7, 237-240.

DOI: $10.1016 /$ j.jfms.2004.12.006

BOYD, C., M. CLAUS, G. HOSGOOD, L. SMART (2017): Survival of two dogs with pyothorax secondary to perforating oesophageal foreign body. Aust. Vet. J. 95, 41-45.

DOI: $10.1111 /$ avj.12548

DEROY, C., J. B. CORCUFF, F. BILLEN, A. HAMAIDE (2015): Removal of oesophageal foreign bodies: comparison between oesophagoscopy and oesophagotomy in 39 dogs. J. Small Anim. Pract. 56, 613-617.

DOI: 10.1111 jsap. 12386

GIANELlA, P., N. S. PFAMMATTER, I. A. BURGENER (2009): Oesophageal and gastric endoscopic foreign body removal: complications and follow-up of 102 dogs. J. Small Anim. Pract. 50, 649-654.

DOI: 10.1111/j.1748-5827.2009.00845.x

HOUlTON, J., M. E. HERRTAGE, P. M. TAYLOR, S. M. WATKINS (1985): Thoracic oesophageal foreign bodies in the dog: a review of ninety cases. J. Small Anim. Pract. 26, 521-536.

DOI: $10.1111 / \mathrm{j} .1748-5827.1985 . t b 02230 . x$

JUVET, F., M. PINILLA, R. E. SHIEL, C. T. MOONEY (2010): Oesophageal foreign bodies in dogs: factors affecting success of endoscopic retrieval. Irish Vet. J. 63, 163 - 168.

DOI: $10.1186 / 2046-0481-63-3-163$

KEIR, I., L. WOOLFORD, C. HIRST, S. ADAMANTOS (2010): Fatal aortic oesophageal fistula following oesophageal foreign body removal in a dog. J. Small Anim. Pract. 51, 657-560.

DOI: 10.1111/j.1748-5827.2010.01012.x

KING, J. M. (2001): Esophageal foreign body and aortic perforation in a dog. Veterinary medicine $96,828-828$.

LEIB, M. S., L. L. SARTOR (2008): Esophageal foreign body obstruction caused by a dental chew treat in 31 dogs (2000-2006). J. Am. Vet. Med. Assoc. 232, 1021-1025.

DOI: $10.2460 /$ javma.232.7.1021

LUTHI, C., R. NEIGER (1998): Esophageal foreign bodies in dogs: 51 cases (1992-1997). Eur. J. Comp. Gastroenterol. 3, 7-11.

MOORE, A. H. (2001): Removal of oesophageal foreign bodies in dogs: use of the fluoroscopic method and outcome. J. Small Anim. Pract. 42, 227-230.

DOI: 10.1111/j.1748-5827.2001.tb02025.x

POLLOCK, S. (1969): Esophageal foreign body in the dog. J. Am. Vet. Med. Assoc. 155, 531-534. 
I. Šmit et al.: Endoscopic removal of esophageal and gastric foreign bodies in dogs

ROUSSEAU, A., J. PRITTIE, J. D. BROUSSARD, P. R. FOX, J. HOSKINSON (2007): Incidence and characterization of esophagitis following esophageal foreign body removal in dogs: 60 cases (1999-2003). J. Vet. Emerg. Crit. Care. 17, 159-163.

DOI: $10.1111 /$ j.1476-4431.2007.00227.x

SALE, C. S., J. M. WILLIAMS (2006): Results of transthoracic esophagotomy retrieval of esophageal foreign body obstructions in dogs: 14 cases (2000-2004). J. Am. Anim. Hosp. Assoc. 42, 450-456.

DOI: $10.5326 / 0420450$

SEILER, G., U. RYTZ, L. GASCHEN (2001): Radiographic diagnosis - cavitary mediastinal abscess. Vet. Radiol. Ultrasound 42, 431-433.

DOI: $10.1111 / j .1740-8261.2001 . t b 00965 . x$

SHERDING, R. G. (2013): Esophageal foreign body. In: Canine and Feline Gastroenterology. (Washabau, R. J., M. J. Day, Eds.), Elsevier Sounders, St. Louis, pp. 576-577.

SPIELMAN, B. L., E. H. SHAKER, M. S. GARVEY (1992) Esophageal foreign body in dogs: a retrospective study of 23 cases. J. Am. Anim. Hosp. Assoc. 28, 570-574.

STURGESS, C. P. (2000): Diseases of the alimentary tract. In: Textbook of Small Animal Medicine. (Dunn, J. K., Ed.), W.B. Saunders, London, Edinburgh, New York, Philadelphia, Sydney, Toronto, pp. 371-447.

TAMS, T. R. (2003): Diseases of the esophagus. In: Handbook of Small Animal Gastroenterology. (Tams, T. R., Ed.), Elsevier Science, St. Luis, pp. 118-158.

DOI: 10.1016/B978-0-7216-8676-9.50008-9

THOMPSON, H. C., Y. CORTES, K. GANNON, D. BAILEY, S. FREER (2012): Esophageal foreign bodies in dogs: 34 cases (2004-2009). J. Vet. Emerg. Crit. Care 22, 253-261.

DOI: 10.1111/j.1476-4431.2011.00700.x

ZIMMER, J. F. (1984): Canine esophageal foreign bodies: endoscopic, surgical, and medical management. J. Am. Anim. Hosp. Assoc. 20, 669-677.

\section{ŠMIT, I., M. CRNOGAJ, M. BRKLJAČIĆ, D. POTOČNJAK, M. TORTI, I. KIŠ, V. MRLJAK, I. JOVIĆ, V. MATIJATKO: Strana tijela u jednjaku i želucu pasa: učestalost, čimbenici rizika i uspješnost endoskopskog vađenja. Vet. arhiv 88, 481-496, 2018.}

\section{SAŽETAK}

Ezofagealna i želučana strana tijela česta su u pasa i mogu biti opasna za život. Endoskopsko uklanjanje stranih tijela iz jednjaka i želuca preporučena je i manje invazivna metoda liječenja, ali nije bez rizika. Ovim su retrospektivnim istraživanjem obuhvaćeni arhivski podaci 100 pasa iz ambulantnog protokola, koji su podvrgnuti endoskopskom uklanjanju stranog tijela iz jednjaka ili želuca. Obrađeni podaci uključivali su dob, pasminu, spol, trajanje i vrstu kliničkih znakova, tip i lokaciju stranog tijela, uspješnost endoskopskog uklanjanja, 
I. Šmit et al.: Endoscopic removal of esophageal and gastric foreign bodies in dogs

kratkotrajne komplikacije i ishod. Najčešća su strana tijela u jednjaku bile kosti, dok su u želucu to bile igračke. U pasa u kojih je zabilježeno dulje trajanje simptoma, utvrđena je veća vjerojatnost za pojavu komplikacija. Iako je ukupna pojavnost komplikacija niska, mogu se razviti potencijalno životno ugrožavajuće komplikacije, osobito u prolongiranim i neliječenim slučajevima stranog tijela u jednjaku, odnosno u slučajevima kada je strano tijelo u želucu oštar predmet sklon perforaciji.

Ključne riječi: pas; strano tijelo; jednjak; želudac; endoskopija 